\title{
Study on the purifying effect of three kinds of hydrophyte upon polluted water
}

\author{
SUN Peng ${ }^{1}$, CUI Kangping ${ }^{2}$, XU Weiyi ${ }^{2}$, WANG Zheng $^{2}$, CHEN Honghan ${ }^{1}$ \\ ${ }^{1}$ School of water resources \& Environment, China University of Geosciences, China \\ ${ }^{2}$ School of Resources and Environmental Engineering, Hefei University of Technology, China \\ piaofeixue_sp@163.com
}

\begin{abstract}
Keywords: Aquatic plants, Ecological floating-beds, Nitrogen and phosphorus uptake, Contaminated waters, Water quality improvement.

Abstract. Three types of local plants (canna, calamus, umbrella,)were chosen to construct ecological floating-beds for contamination control atshiyanbaierhe. Differences in plant growth and the capacity of sewage treatment were compared. Results showed that three plants can uptake the nitrogen, phosphorus and organic matter in water effectively, but significant differences were found among these three species in absorption. The removal rates of CODcr using above plants were ranged from $50.1 \%$ to $75.6 \%$, those of TN were between $50 \%$ to $69.3 \%$ and TP were between $70.4 \%$ to $89.2 \%$. The efficiency of these three plants from high to low is canna calamus and umbrella. Canna had the largest net increase of biomass while umbrella had the smallest. The content of nitrogen and phosphorus in overground parts of plants were higher, thus the nutrient could be transferred from water by reaping the plants. It was recognized that canna could be the best plant to employ on the ecological floating-beds in baierhe area and could mix with calamus in order to improve the ecological diversity.
\end{abstract}

\section{Introduction}

Ecological floating bed becomes an ecological treatment technology with wider application because of its advantages of low cost, simple operation, better landscape benefit, etc. [1].

Ecological floating bed has stronger uptake and absorption ability on nitrogen, phosphorus and organic matters in water. Selection of ecological floating bed plant is also one of research keys for many scholars. Floating beds in different plant types have different effects in nitrogen and phosphorus removal effects [2]. Plant screening of eutrophication waters such as lakes, rivers, etc. is mainly studied currently. There are rare reports about growth features and planting configuration of plants for treating agritourism domestic sewage. In the study, three common floating-bed plants in Shiyan Baier River basin are selected, namely canna, calamus and umbrella. Growth features of the three plants in treating river waters polluted by agritourism domestic sewage as well as their differences in water quality index processing ability of water are studied, thereby providing reference for purifying water quality in Shiyan Baier River and surrounding areas, constructing, promoting and applying plant ecological floating bed system.

\section{Material and methods}

\section{Test materials}

Water sample 20L is added into plastic bin with dimension of $40 \mathrm{~cm}$ (length) x $28 \mathrm{~cm}$ (width) x 30 $\mathrm{cm}$ (height). Polyethylene plastic foam board with thickness of about $1.5 \mathrm{~cm}$ is adopted as carrier, which is punched for planting aquatic plants. The water tank is placed on the balcony in the laboratory.

Plants are selected according to local climate conditions of Shiyan through comprehensively considering the purification effect of plants. Three common advantage floating-bed plants are selected as research objects, namely canna, calamus and umbrella.

Water for the test is taken from Baier River. Average values of COD, TN and TP concentrations in test water are respectively $107 \mathrm{mg} / \mathrm{L}, 15 \mathrm{mg} / \mathrm{L}$ and $3.7 \mathrm{mg} / \mathrm{L}$ according to measurement. 


\section{Test method}

Four groups were totally set for treatment in the test, including three plant groups and one control group. Each test group was repeated for three times. One plant was cultivated for treatment in each group. Canna, umbrella, calamus and blank group were respectively numbered as 1, 2, 3 and 4 . River water was contained in box of the control only. The test was implemented from August 5 to September 22, 2014 with duration of 49 days. Water samples of all groups were collected on 10:00a.m on the third day with interval of two days according to $50 \mathrm{ml}$ each time.

\section{Determination method}

Water quality(COD, Total phosphorus, Total nitrogen, Ammonia nitrogen) is determined in accordance with 'Method for Monitoring and Analyzing Water and Wastewater' (state environmental protection administration, 2002). Turbidity was determined according to spectrophotometry. Plant nitrogen and phosphorus were determined after digestion with concentrated sulfuric acid + hydrogen peroxide.

\section{Results and discussion}

\section{Growth condition of plants}

Height, root length and total weight of three plants in different treatment groups were respectively determined at the beginning and ending of test. Three plants can grow normally during test. Height and root length of three plants were increased from the beginning to ending of the test, wherein canna growth condition was significantly better than the other two plants with faster leaf growth, more root growth and growth of a lot white new roots. Plant height growth rate and root length growth rate were $17.5 \%$ and $62.5 \%$ respectively; Canna was followed by calamus, and umbrella showed general growth condition in the test with the minimum height and plant increase (please see Tab.1).

Table.1 Growth of aquatic vegetative

\begin{tabular}{ccccccc}
\hline Plant & \multicolumn{2}{c}{ Height $(\mathrm{cm})$} & Growth rate & \multicolumn{2}{c}{ Maximum root length $(\mathrm{cm})$} & Growth rate \\
& Beginning & Ending & & Beginning & Ending & \\
\hline Canna & 40 & 47 & $17.5 \%$ & 8 & 13 & $62.5 \%$ \\
Umbrella & 44 & 46 & $4.5 \%$ & 5 & 6 & $20 \%$ \\
Calamus & 38 & 42 & $10.5 \%$ & 15 & 17 & $13.3 \%$ \\
\hline
\end{tabular}

\section{Water quality indicator removal effect}

Concentration change of chemical oxygen demand (COD) in water. Figure 1 shows that three aquatic plants have better removal effect on COD in contaminated water. The removal change rules are basically similar, the removal rate is decreased more rapidly in the initial stage, which is slightly returned in the middle stage, and faster removal level was recovered until it was balanced. Removal effect is canna > calamus > umbrella > blank. Removal rate is $75.6 \%, 65.9 \%, 50.1 \%$ and $29.7 \%$ respectively.

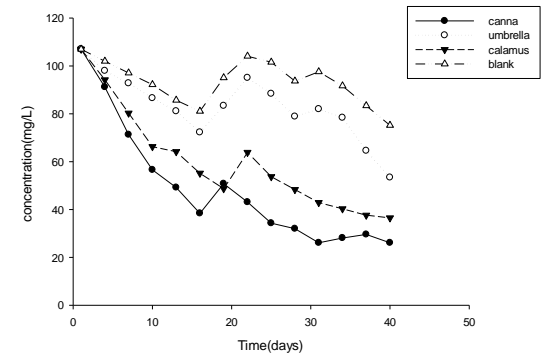

Figure. 1 The change curve of COD

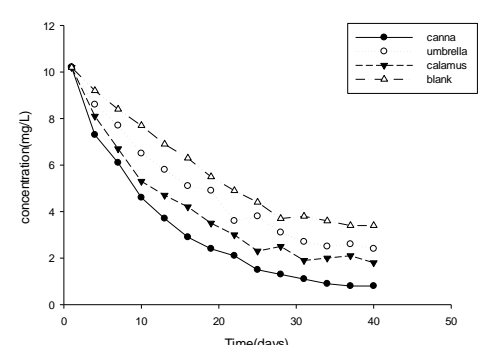

Figure. 2 The change curve of $\mathrm{NH}_{4}{ }^{+}-\mathrm{N}$

Concentration change of ammonia nitrogen in water. Removal effect of different test groups on ammonia nitrogen is shown in figure 2 . The removal rate of test groups with plant was prominently higher than the blank test group as control. The removal effect is canna $>$ calamus $>$ umbrella $>$ blank. The removal rate is $92.2 \%, 82.4 \%, 76.5 \%$ and $66.7 \%$ respectively.

Concentration change of total nitrogen in water. The removal effect of total nitrogen during the test process is shown in figure 3. Three plants have prominent effect in removing total nitrogen. Different test groups are compared, it is obvious that three aquatic plants have more prominent 
difference in total nitrogen removal effect, namely canna $>$ calamus $>$ umbrella $>$ blank, and the removal rate is $69.3 \%, 61.3 \%, 50 \%$ and $42.7 \%$ respectively.

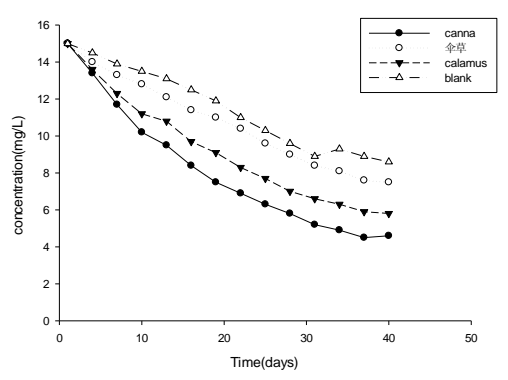

Figure. 3 The change curve of TN

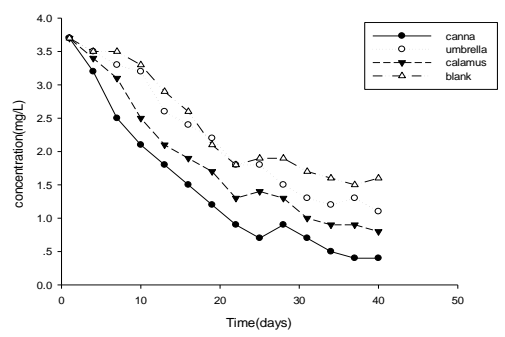

Figure.4 The change curve of TP

Concentration change of total phosphorus in water. Fig. 4 shows that different test groups have better removal effect on total phosphorus. The removal difference among different test groups is prominent. The removal effect of canna is better than other three test groups at the end of test, which is followed by calamus, umbrella and blank groups with poor effect. The removal rate is $89.2 \%$, $78.4 \%, 70.4 \%$ and $56.9 \%$ respectively.

\section{Nitrogen and phosphorus contents in plant}

Nitrogen and phosphorus can be removed out of waters through absorption of plant on nitrogen and phosphorus as well as nitrogen removal by denitrification of ecological floating-beds, thereby playing the role of controlling water eutrophication.

Table. 2 shows that three plants were cultivated, canna grows from $67 \mathrm{~g}$ to $86 \mathrm{~g}$ with the growth rate of $28 \%$; Calamus grows from $55 \mathrm{~g}$ to $66 \mathrm{~g}$ with growth rate of $20 \%$; Umbrella grows from $63 \mathrm{~g}$ to $72 \mathrm{~g}$ with growth rate of $11.1 \%$. It is obvious that umbrella's adaptability and removal efficiency to eutrophication waters are lower than that of calamus and canna under local climate conditions in Shiyan.

Nitrogen and phosphorus contents accumulated in plant as well as removal contribution rates before and after test were test. Canna totally enriches nitrogen $55.4 \mathrm{mg}$ from waters, and calamus and umbrella respectively enrich nitrogen $41.6 \mathrm{mg}$ and $25.5 \mathrm{mg}$ respectively, which respectively account for $26.7 \%, 22.6 \%$ and $17 \%$ in system removal rate. Enrichment degrees of different tissues are compared. Canna stems and leaves have the maximum accumulation of nitrogen, which is up to $36 \mathrm{mg}$. It is followed by calamus stem and leaf, canna root, calamus root, umbrella stem and leaf as well as umbrella root. The cumulative amounts are $22.3 \mathrm{mg}, 20.6 \mathrm{mg}, 19.3 \mathrm{mg}, 15.3 \mathrm{mg}$ and $11.2 \mathrm{mg}$ respectively. Phosphorus removal rate is canna > calamus > umbrella, accumulation in waters is respectively $3.08 \mathrm{mg}, 2.38 \mathrm{mg}$ and $1.49 \mathrm{mg}$. The contribution rates to system removal are respectively $4.7 \%, 4.1 \%$ and $2.9 \%$.

Table.2 The growth of plants before and after experiment

\begin{tabular}{cccc}
\hline Plant & Plant weight before test $(\mathrm{g})$ & Plant weight after test $(\mathrm{g})$ & Growth rate \\
\hline Canna & 67 & 86 & $28 \%$ \\
Umbrella & 63 & 72 & $11.1 \%$ \\
Calamus & 55 & 66 & $20 \%$ \\
\hline
\end{tabular}

\section{Discussion}

Three groups of aquatic plants shows good removal effect on chemical oxygen demand (COD), ammonia nitrogen, total nitrogen and total phosphorus in the contaminated water during test. Water quality is better improved. Canna and calamus have dense roots, and the root of umbrella is relatively sparse aiming at three plants adopted in the test. Uptake and absorption effect of plant roots on pollutants is important approach for floating-bed plants to purify contaminated waters. Dense roots can increase absorption on suspended matters in the water, be beneficial for the roots to release oxygen to waters, and form aerobic and anoxia small environment of roots. Meanwhile, dense root also can provide good habitats for microorganisms, which is beneficial for increasing microbial species and amount, thereby improving the purification efficiency on polluted river water [3].

Biomass of floating-bed plants is gradually increased in the growth process. Absorption of nitrogen in the contaminated water is gradually increased. The absorption of developed roots of the 
plan to water suspended solids is also continuously increased. In addition, oxygen therapy ability of roots also can be increased by developed roots, dissolved oxygen in the water can be increased, and beneficial conditions are created for developing and reproducing aerobic microorganisms in waters, especially aerobic microorganisms in roots [4].

Cumulative nitrogen and phosphorus contents in plants are analyzed. It is obvious that nitrogen and phosphorus contents in stem and leaf tissues of the selected plant are higher than that in roots, the enriched nitrogen and phosphorus account for larger proportion in the whole system. Therefore, when eutrophication waters is treated by subsequent ecological floating island, tissues of plants above the water surface can be regularly harvested, thereby nutritive salt absorbed and transferred by plant can be transferred out of water on one hand, and plant regeneration ability also can be kept.

\section{Conclusion}

Local canna, calamus and umbrella in Shiyan are tested as ecological floating bed plants, and they are used for studying water quality improvement in Baier River basin. Test results show that nitrogen, phosphorus and other pollutants in eutrophication waters can be effectively absorbed.

The removal efficiency of canna test group on eutrophication waters is obviously higher than that of calamus test group and umbrella test group. Removal efficiency of CODcr, ammonia nitrogen, TN and TP in canna test group is respectively $75.6 \%, 92.2 \%, 69.3 \%$ and $89.2 \%$. The efficiency in calamus group is respectively $65.9 \%, 82.4 \%, 61.3 \%$ and $78.4 \%$. It is the lowest in umbrella group, $50.1 \%$, $76.5 \%, 50 \%$ and $70.4 \%$ respectively.

Nitrogen and phosphorus accumulation amounts of different plants are greatly different. Canna stem and leaf have the maximum accumulation of nitrogen, which is followed by calamus stem and leaf, canna root, calamus root, umbrella stem leaf and umbrella root; The phosphorus removal rate is sequenced as follows: canna stem and leaf, calamus root, canna root, calamus stem and leaf, umbrella root as well as umbrella root and leaf.

Influence of season on floating-bed plants is not considered in the test process. The influence of climate environment factor on growth of advantage plant is increased in subsequent study, and thereby local plants can be further screened in details.

\section{Acknowledgements}

This work was financially supported by the Major projects of water pollution control and management technology (NO.2012ZX07205-002).

\section{References}

[1] Zhang Wenxian, Han Yonghe, Lu Wenxian, et al. Preparation of plants-combined ecological floating bed and its purifying effects for eutrophic water Chinese Journal of Environmental Engineering, 2014,8(8):3253-3258.

[2] Sierp M T, Qin J G, Recknagel F. Biomanipulation: A Review of Biological Control Measures in Eutrophic Water Sand the Potential for Murray cod Maccullochella Peelii Peelii to Promote Water Quality in Temperate Australia. Reviews in Fish Biology and Fisheries, 2009,19(2):143-165.

[3] Brix, H. Do Saprophytes Play A Role in Constructed Treatments. Water Science and Technology, 1997.35 (5):11-17

[4] Zheng Liguo, Yang Renbin, Wang Haiping, et al. Study on water remediation and uptake ability of nitrogen and phosphorus by plants using combined ecological floating bed. Chinese Journal of Environmental Engineering, 2012,7 (6):2153 -2159. 